\title{
Dimensiones de la violencia urbana en la región metropolitana de Rio de Janeiro desde la práctica de una organización que lucha por la paz (2010-2014)*
}

\author{
Santiago Galar* \\ Resumen \\ El artículo explora el problema de la violencia urbana en la \\ región metropolitana de Rio de Janeiro desde la práctica \\ pública de una ONG local. Reparamos en particular en las \\ formas de conceptualizar y accionar por parte de la \\ organización Rio de Paz con relación a homicidios ocurridos en \\ la ciudad, teniendo en cuenta lo realizado por otros actores en \\ el más amplio registro de la acción pública. Con este fin \\ analizamos información institucional y publicaciones en redes \\ sociales de la Organización No Gubernamental, llevamos a cabo \\ observaciones en su sede y nos remitimos a la prensa escrita \\ local de circulación nacional. Como resultado evidenciamos por \\ parte de la ONG operaciones de generalización y de \\ clasificación de las muertes a través de las cuales se manifiestan \\ dimensiones simbólicas y materiales contenidas actualmente en \\ el problema de la violencia urbana en esa ciudad brasileña.
}

\section{Palabras clave}

Activismo-Violencia urbana-Problema Público-Homicidios.

\footnotetext{
* Artículo recibido el 20 de Febrero de 2016. Aceptado el 9 de Septiembre de 2016.

** Instituto de Investigación en Humanidades y Ciencias de la Educación, Universidad Nacional de La Plata y CONICET (IdIHCS, UNLP/CONICET). Mail: santiago_galar@hotmail.com
} 


\section{Abstract}

The article explores the problem of the urban violence in the metropolitan region of Rio de Janeiro from the public practice of a local NGO. We analyze ways of conceptualize and act of the organization Rio de Paz in the context of murders that happened in the city considering what has been done by other actors in the wider record of the public action. As sources we use institutional information and publications on social networks of the NGO, interviews and observations and we analyze the local press. As a result we present operations of generalization and classification of deaths by the NGO that shows the diversity of variables involved in the problem of urban violence in Rio de Janeiro.

\section{Keywords}

Activism-Crime-Public Problem-Murders.

\section{Introducción}

Reparamos en este trabajo en la práctica de Rio de Paz (RDP), una ONG que acciona en torno al problema de la violencia urbana y en particular sobre aquello que considera su manifestación extrema: los homicidios ${ }^{1}$. Analizamos la práctica de esta organización poniendo énfasis en las formas de conceptualización y acción que sus miembros sostienen ante homicidios frente a los cuales se movilizaron públicamente en los últimos años. El objetivo de este artículo es indagar a través de este ángulo en relación con dimensiones de la violencia urbana entendidas como problema público en la región metropolitana de Rio de Janeiro entre 2010 y 2014.

La elección de RDP radica, por un lado, en la visibilidad obtenida por esta ONG a través de la denuncia pública de la ocurrencia de homicidios y, por otro, en el carácter local de la entidad. Seleccionamos los homicidios que reconstruimos en el registro de

\footnotetext{
${ }^{1}$ La presente investigación fue realizada en 2014, durante una estancia en el Programa de Posgrado en Antropología de la Universidad Federal Fluminense de Rio de Janeiro, financiada por la beca Roberto Carri del Ministerio de Educación de la Nación y el Consejo de Decanos de las Carreras de Ciencias Sociales y Humanidades.
} 
la acción pública de un listado de muertes por las cuales RDP movilizó recursos en el espacio público. En esta selección fueron tenidas en cuenta las clasificaciones utilizadas por la organización y el interés por incluir decesos ocurridos en diversas zonas de la región metropolitana. Utilizamos como fuentes para la reconstrucción de eventos ligados a los homicidios seleccionados a la prensa escrita local de circulación nacional: los diarios O Día (OD), Jornal do Brasil (JDB) y Extra de O Globo (EX) ${ }^{2}$ Sostenemos que pese a los sesgos y limitaciones de las fuentes periodísticas, su análisis permite dar cuenta de acontecimientos múltiples y simultáneos producidos en el registro de la acción pública en relación con cada caso. Además, utilizar a la prensa como fuente posibilita poner en vínculo la práctica de RDP con la de otros actores constituyentes de la arena pública. Para el análisis de la práctica de RDP con respecto a los homicidios, recurrimos asimismo a información institucional de la organización -página web, blogs, comunicados-, publicaciones en redes sociales -Facebook, Twitter, YouTube- y a observaciones realizadas en la sede de la ONG, ubicada en la comunidad de Jacarezinho ${ }^{3}$.

El análisis de la performance pública frente a determinados homicidios por parte de la institución visibiliza operaciones de generalización y de clasificación de las muertes. Sostenemos que el análisis de estas operaciones permite avanzar en el planteo de la diversidad de dimensiones implicadas en la constitución del problema público de la violencia urbana en la región metropolitana de Rio de Janeiro.

\section{Experiencia pública}

El objeto de nuestra indagación es la práctica de un colectivo que se organiza en torno a la denuncia pública del problema de la violencia en Rio de Janeiro. En este sentido, entendemos al espacio público como el punto de intersección entre diversos campos sociales comprendido por acciones realizadas para ser "vistas y oídas" (François

\footnotetext{
2 El registro de prensa escrita consta de 375 ítems producidos con relación a los casos analizados entre julio de 2010 y diciembre de 2014. Para evitar una lectura engorrosa, solo colocamos fuentes en caso de citas textuales, las cuales aparecen traducidas al español y entre comillas.

${ }^{3}$ Ubicada junto a una vía férrea en la zona norte de la ciudad, la comunidad de Jacarezinho es una de las mayores favelas de Rio de Janeiro. Realizamos visitas a la sede de RDP en noviembre de 2014, allí participamos de reuniones y de conversaciones informales con sus miembros. El registro de información institucional consta de 40 ítems y el de redes sociales, de 71.
} 
De Prácticas y discursos/ Universidad Nacional del Nordeste/ Centro de Estudios Sociales

y Neveu, 1999). Así entendido, el carácter público de un acontecimiento ingresa en el registro de la acción pública, una dimensión que se sostiene en experiencias que movilizan referencias al bien común a través de las cuales se conforman arenas donde interactúan actores, instituciones y prácticas (Schillagi, 2011). Estas interacciones entre diversos campos sociales, exploradas desde registros discursivos y prácticas donde los primeros se encarnan, se conciben como eminentemente conflictivas.

Entender a la violencia urbana como un problema público implica suponer la existencia de un modo de definir cierta situación como problemática y la consiguiente demanda de soluciones por parte de diferentes públicos organizados alrededor de determinada categoría (Pereyra, 2013). En nuestro caso, RDP disputa en cooperación y tensión con otros actores la propiedad sobre el problema de la violencia, es decir, la posibilidad de erigirse como enunciador privilegiado de la definición del problema (Gusfield, 2014). Además, en la estructura de todo problema público resultan fundamentales las imputaciones de responsabilidad realizadas por los actores; tanto la responsabilidad causal, vinculada al modo en que se produjo un problema, como la responsabilidad política, vinculada a la obligación de quienes deben actuar para solucionarlo. Estos elementos estructurales de los problemas públicos -la propiedad, la causalidad y la obligación- pueden no coincidir en un mismo actor, cuestión que le otorga dinamismo a la disputa pública.

Ahora bien, nuestro análisis se basa en la movilización de RDP ante homicidios constituidos públicamente como casos conmocionantes. Con la noción de caso nos referimos a una construcción que difiere de una mera producción espacio-temporal de hechos. Puntualmente diferenciamos al caso conmocionante de la ocurrencia del homicidio que constituye su origen. En la generación de mediaciones sociales entre la muerte y su constitución como caso, en el proceso de adquisición de carácter público de una muerte, es central la movilización de actores en el espacio público. Más allá de las características truculentas de un crimen, el logro de la atención pública depende de la práctica de múltiples actores en diferentes instancias, aunque detenten objetivos e intereses en tensión. Acontecimiento y constitución de públicos están íntimamente 
De Prácticas y discursos/ Universidad Nacional del Nordeste/ Centro de Estudios Sociales

articulados por el concepto de experiencia pública porque es en este registro que las muertes se constituyen como acontecimientos públicos (Galar, 2015).

\section{Escenario local}

La ciudad de Rio de Janeiro es mundialmente reconocida como una de las capitales globales de la violencia urbana y, simultáneamente, la violencia urbana posee notable centralidad en las preocupaciones públicas locales. En sintonía con estas preocupaciones, las ciencias sociales brasileñas manifestaron en las últimas décadas un interés pujante y sostenido en procesos ligados a la violencia, la criminalidad, la seguridad pública y la justicia criminal (Kant de Lima et al., 2000). En lo que sigue presentamos mediante grandes pinceladas algunos procesos significativos vinculados a la producción de homicidios en Rio de Janeiro.

En el Brasil, la tasa de homicidios en 2012 fue de 25.2 cada cien mil habitantes y representó el $11 \%$ de los homicidios producidos a nivel mundial (Rojido Fiori, 2014). En términos absolutos, Waiselfisz (2013) destaca que entre 2008 y 2011 se produjeron en el país 206 mil muertes por homicidios, número similar al generado por la totalidad de los conflictos armados ocurridos en el mundo en el mismo período. Al atender a dinámicas temporales, las tasas de violencia homicida en el Brasil comenzaron a crecer desde 1980, luego esta tendencia se revirtió en torno a 2003/4 para retomar un tenue crecimiento desde 2007. En términos espaciales, las investigaciones reparan en que la tasa de homicidios se distribuye heterogéneamente en el territorio. El estado de Rio de Janeiro ocupa una posición intermedia y cercana a la media nacional, con 23.5 crímenes cada cien mil habitantes en 2012 (Waiselfisz, 2013). Y prestando atención a la caracterización de las víctimas, en 2011 más de la mitad de los muertos en homicidios fueron jóvenes (52.63\%), de los cuales el 74\% era "negros o pardos" y el 93\%, varones (Rojido Fiori, 2014). De esta manera, en correspondencia con las tendencias internacionales, los hombres se destacan como víctimas y victimarios, un riesgo mayor en caso de personas jóvenes y de "raza no blanca" (Cano y Ribeiro, 2007; SerranoBerthet y Chioda, 2012). Cabe destacar en este punto que las estadísticas oficiales de homicidios, usualmente ponderadas por su alto nivel de registro, poseen sesgos 
De Prácticas y discursos/ Universidad Nacional del Nordeste/ Centro de Estudios Sociales

derivados de las acciones, decisiones y formas de pensar el mundo de los actores que las producen. En este sentido, al seguir a Mendes de Miranda y Pita (2011), subrayamos que esta característica compartida por toda producción de estadísticas oficiales implica particularidades en el campo de la criminalidad, por involucrar actores específicos policiales, judiciales, penitenciarios- y constituir una descripción de "la realidad" que impacta en la construcción de un problema público jerarquizado en las preocupaciones ciudadanas.

Las grandes metrópolis se constituyen como espacios privilegiados para la ocurrencia de conflictos que derivan en muertes violentas, por factores como la concentración poblacional, la impersonalidad de las relaciones y el acceso a armas de fuego (Alves Diniz et al., 2013). En el caso de Rio de Janeiro, además, se destaca la centralidad en la dinámica de producción de homicidios de procesos asociados al crimen organizado en general y al narcotráfico en particular. Estos procesos influyen tanto en la emergencia de actores en disputa -sectores policiales, traficantes, miliciascomo en la constitución de un complejo patrón de violencia urbana (Misse, 2009). Finalmente, sumando complejidad al escenario, en las últimas décadas Rio de Janeiro se convirtió en un polo de turismo global y en la sede de mega-eventos internacionales, procesos que impactaron en su rediseño urbano y en la redefinición de las formas del ejercicio del poder (Vainer, 2010).

De esta manera, el Estado de Rio de Janeiro posee una tasa de homicidios alta, al tiempo que cercana a la media nacional, en un escenario dinamizado por un patrón de violencia en el cual el crimen organizado ocupa un lugar destacado por su influencia en las relaciones entre actores y prácticas legales e ilegales. En sinergia con la creciente preocupación social en torno al delito, la violencia urbana fue paulatinamente incorporada como tema central de la agenda pública local y nacional. Sin embargo, no se trata de una mera incorporación, sino de una construcción colectiva de la cual participan actores que trascienden a la política institucional y a las fuerzas de seguridad, entre los que se destacan las organizaciones de la sociedad civil (Leilah y Raíza, 2013). 


\section{Un Río de Paz}

Según el discurso institucional, la creación de RDP se produjo en 2007 cuando un grupo de personas "rompió con la inercia de los ciudadanos" al colocar cientos de cruces en la playa de Copacabana con el objetivo de visibilizar una "ola de crímenes" acontecida en la ciudad ${ }^{4}$. Este grupo se conformó tiempo después como una organización abocada al problema de la violencia, con una fuerte presencia pública de su principal referente, un pastor y teólogo local de orientación calvinista llamado Antônio Costa. Los integrantes de RDP pertenecen a diversos credos, pero su discurso institucional no manifiesta apelaciones religiosas, sino más bien un perfil humanista anclado en ciertos valores compartidos.

La organización se presenta como un "movimiento" compuesto por "ciudadanos brasileños" que "ejercen sus derechos" y son "agentes de cambio". Esta moral ciudadana posee un correlato en la práctica pública de la ONG en tanto sus miembros reivindican un accionar "pacífico" que asimilan a lo civilizado. RDP se reconoce también como un movimiento "de clase media" que mientras sostiene una voz propia, procura "dar voz a quienes no tienen voz y visibilidad a los invisibles", volverse "portavoz" de quienes "no tienen fuerzas para reivindicar sus derechos". Por esto, desde el saberse incluidos -aunque no escuchados- los integrantes de RDP reconocen a un otro excluido a quien intentan dar entidad -"los pobres", "los habitantes de las comunidades"-. Finalmente, a diferencia de gran parte de las organizaciones abocadas a la violencia urbana, la categoría "víctima" no es central en las valoraciones morales planteadas por RDP en su accionar público-político ${ }^{5}$. Además, plantea un vínculo de distancia y control con "los poderes públicos" y los partidos políticos bajo el argumento de proteger su autonomía como organización.

\footnotetext{
${ }^{4}$ Landim y Siqueira (2013) destacan que las organizaciones civiles dedicadas a la violencia urbana en Rio de Janeiro suelen vincular su origen a un "evento crítico" cargado de simbolismo, sea un hecho de magnitud -como las masacres conocidas como chacinas-, sucesiones de eventos dramáticos o muertes individuales.

${ }^{5}$ En su análisis de organizaciones movilizadas ante la violencia en Rio de Janeiro y Rio Grande do Sul, Arosi (2013) sostiene que estas organizaciones se centran mayoritariamente en la "víctima" como categoría política desde donde despliegan valoraciones y jerarquizaciones sobre el sufrimiento, el dolor y las vidas que merecen ser vividas.
} 
De Prácticas y discursos/ Universidad Nacional del Nordeste/ Centro de Estudios Sociales

Los miembros de RDP intervienen alrededor de tres tipos de actividades. En primer lugar, sostienen "proyectos sociales" en "comunidades pobres" con el fin de "reintegrar a los excluidos", principalmente capacitaciones en diversos oficios. En segundo lugar, realizan manifestaciones e intervenciones urbanas caracterizadas por un lenguaje artístico truculento a través de las cuales buscan visibilizar el problema de la violencia y demandar soluciones a las autoridades. Finalmente, desde la ONG se producen "estadísticas sobre violaciones a derechos humanos" en Rio de Janeiro. En este sentido, RDP difunde mensualmente en las redes sociales estadísticas desagregadas en las categorías "Homicidio doloso", "Lesión corporal seguida de muerte", "Latrocinio", "Homicidio producto de intervención policial", "Policías militares muertos en servicio", "Policías civiles muertos en servicio" $y$, separadamente, "Desaparecidos" y "Tentativas de Homicidio". Estas cifras también son difundidas en el marco de las intervenciones urbanas, en tanto la ONG "utiliza los datos sobre la violencia para alertar a la sociedad civil y demandar medidas a las autoridades" (YouTube, abril 2014).

El problema a abordar para RDP es la violencia y su manifestación evidente es la magnitud cuantitativa y cualitativa alcanzada por la producción de homicidios en el país y en la ciudad. Para RDP, la responsabilidad política -en los términos de Gusfield (2014)- recae en "las autoridades" por ser quienes deberían encontrar soluciones. Además, en un nivel diferenciado e inferior, recae en "la ciudadanía", colectivo que debería involucrarse, controlar y exigir a "las autoridades". Por otro lado, RDP no realiza imputaciones concretas en relación con la violencia, sino señalamientos genéricos que tienden a socializar las responsabilidades: "la impunidad mata", "votar mal mata", "la indiferencia mata".

Finalmente, RDP deriva cierta conceptualización sobre los derechos humanos de una condena genérica a "la muerte" según la cual "donde haya gente matando estará nuestra oposición, donde haya gente muriendo estará nuestra protesta" (Facebook, julio 2014). En este sentido, la ONG pretende trascender tensiones presentes en el campo de las organizaciones civiles que abordan la violencia, tanto la "aversión al lenguaje de los derechos humanos" como la focalización de los derechos en 
De Prácticas y discursos/ Universidad Nacional del Nordeste/ Centro de Estudios Sociales

determinados colectivos (Landim y Siqueira, 2013). RDP plantea una concepción de derechos humanos que considera amplia y a través de la cual disputa en torno a la necesidad de su efectiva universalización al asegurar "nosotros no queremos la muerte de nadie, solo es eso" (Facebook, enero 2013).

\section{Homicidios conmocionantes en el registro de la acción pública}

Reconstruimos a continuación eventos significativos manifiestos en el registro de la acción pública vinculados a cinco homicidios frente a los cuales RDP movilizó recursos en el espacio público. Por un lado, daremos cuenta de actores participantes, prácticas y valoraciones sostenidas con miras a poner en contexto el accionar público de RDP. Por otro lado, centraremos la atención en la práctica y las valoraciones sostenidas por la ONG en el proceso de adquisición de carácter público de las muertes en cuestión.

Se trata de homicidios que desde la ONG fueron puestos en equivalencia al considerarlos manifestaciones de la violencia, pero que al mismo tiempo fueron diferenciados mediante clasificaciones sobre las formas de morir y a partir de caracterizaciones sobre los muertos. Un referente de RDP afirmó que desde la ONG suelen movilizarse "ante casos que causan conmoción, no todos, porque estaríamos todo el tiempo en las calles". La organización irrumpe en el espacio público ante homicidios que consideran significativos, mediante los cuales intentan interpelar a la sociedad en relación con el problema de la violencia.

\subsection{Muertes y desaparición de cuerpos: “¿dónde está Amarildo?”}

El albañil Amarildo Souza desapareció en la Rocinha en julio de 2013, luego de ser ilegalmente detenido por agentes de la Unidad de Pacificación (UPP) en el marco de una operación militar. La versión de la Policía Militar (PM) aseguraba que Amarildo había sido demorado por supuestos vínculos con el narcotráfico y que minutos después había sido liberado, abandonando la UPP por sus medios. Sin embargo, un conjunto de indicios y contradicciones fortalecieron la sospecha sobre el accionar policial. Por este motivo, los medios de comunicación en sinergia con referentes 
De Prácticas y discursos/ Universidad Nacional del Nordeste/ Centro de Estudios Sociales

sociales y políticos otorgaron visibilidad al caso. Finalmente se consolidó en los medios la versión de que Souza había muerto por las torturas sufridas en la sede de la UPP y que su cuerpo había desaparecido bajo directivas del comandante de la Unidad. Por el caso fueron imputados veinticinco policías acusados de "tortura seguida de muerte" y "ocultamiento del cadáver". Durante la investigación, la Justicia realizó múltiples rastrillajes y dio con cuerpos que no correspondían con el de la víctima. La familia de Souza sostuvo reclamos por la aparición del cuerpo y logró la declaración del "estado de muerte presumida" con miras a iniciar acciones civiles al Estado.

Alrededor de la pregunta "¿dónde está Amarildo?" se articuló un movimiento heterogéneo, parcialmente contenido por el simultáneo clima de protesta vinculado al descontento ante los gastos originados por la organización de la copa mundial de fútbol. Frente al caso se realizaron constantes intervenciones de usuarios de redes sociales y manifestaciones en Rio de Janeiro, en otras ciudades brasileñas y en el exterior del país. Además, miembros de la comunidad artística se movilizaron ante el caso, por ejemplo durante la campaña Todos somos Amarildo, en la cual reconocidos cantantes recaudaron fondos para la familia del albañil y organizaciones de derechos humanos. La desaparición de Souza permitió (re)abrir discusiones sobre las formas de intervención del Estado en las comunidades, la práctica de desaparición de personas y la existencia de "cementerios clandestinos". Las autoridades políticas estaduales y policiales calificaron al caso como "un incidente aislado" y defendieron la política de "pacificación". Al mismo tiempo, a instancias del caso fueron visibilizadas denuncias de vecinos de la Rocinha sobre abusos policiales y fue públicamente discutida la desconfianza de la ciudadanía hacia la institución policial. Asimismo, se desarrolló una importante actividad legislativa, con iniciativas como la creación de una comisión en el nivel estadual para el seguimiento de causas de desaparición de personas y la convocatoria a audiencias públicas con miras a la creación de un área dedicada al tema en la Secretaría de Seguridad. Producto y consecuencia de estos procesos, el caso fue convertido en un emblema de la violencia policial.

En este contexto, RDP actuó en diversas direcciones: se reunió con familiares de Amarildo, realizó campañas en las redes sociales para colaborar con la familia e 
De Prácticas y discursos/ Universidad Nacional del Nordeste/ Centro de Estudios Sociales

incentivar la denuncia de la violencia policial, y colocó pancartas en el Cristo Redentor y en la Rocinha. También realizó una manifestación en Copacabana, donde la pregunta por el paradero de Amarildo fue acompañada por maniquíes envueltos en telas que luego fueron enterrados en la arena. Según Antônio Costa, el propósito de las iniciativas era "presionar a las autoridades políticas para que den una rápida solución al caso" y visibilizar la desaparición entre 2007 y 2013 de 35 mil personas con miras a que "el pueblo salga a la calle" (JB, 31/07/2013). Además, RDP lanzó la campaña "desaparecidos en democracia, personas reales, víctimas invisibles" y solicitó controles a la actividad policial. Por último, junto a otras organizaciones, la ONG propició la apertura de una comisaría abocada a la desaparición de personas. RDP subrayó que de no significar "un punto de inflexión", el caso Amarildo se convertiría en "un franco retroceso": "torturar, matar y ocultar el cadáver de la víctima es atroz. No estamos haciendo preguntas sobre el carácter de la víctima, sino sobre la autoría del delito" (Facebook, octubre 2013).

\subsection{Muertes por balas perdidas: "todo ser humano tiene derecho a la vida"}

En julio de 2010, Wesley de Andrade, de 11 años, murió de un disparo en el pecho mientras se encontraba en una escuela en Costa Barros, zona sur de la ciudad. La PM realizaba en las inmediaciones una operación en la cual murieron también otras cinco personas catalogadas como "bandidos". Como primera reacción, la Secretaría Municipal de Educación envió a la escuela un equipo de profesionales para la contención de padres y alumnos, adelantó el receso invernal y dispuso un retorno a clases "con actividades educativas y debates". Paralelamente, según los medios, algunos padres manifestaron la intención de cambiar a sus hijos de escuela. Además, representantes del gremio educativo renovaron la demanda de medidas de seguridad. Desde la Secretaría de Educación relanzaron una propuesta para blindar las ventanas de escuelas ubicadas en "zonas peligrosas" de la ciudad, aunque finalmente se limitaron a construir un muro perimetral a la escuela en cuestión. La seguridad en las escuelas se renovó como tema de debate, con especial énfasis en los riesgos presentes 
al interior de los establecimientos ${ }^{6}$. La muerte de Wesley (re)habilitó asimismo la discusión pública sobre las tácticas de la PM en las comunidades. En este sentido, ante declaraciones críticas del padre del niño, el gobernador del estado aseguró que el mejor homenaje sería "continuar firme en el trabajo de pacificación" (OD, 21/07/2010). Además, presionado por este y otros casos, el coronel de la PM resolvió que las acciones desarrolladas por los batallones serían desde entonces previamente comunicadas al comando central. Por último, la cúpula de la PM exoneró al comandante a cargo de la operación, quien reaccionó asegurando públicamente que en la operación "no hubo errores" y que la muerte de inocentes "eventualmente acontecería" (OD, 19/07/2010).

Conocida la muerte, integrantes de RDP se manifestaron en Copacabana representando la escena de una escuela en la cual aparecía un grupo de niños tristes, un profesor con las manos atadas, una pancarta con la convención de Derechos Humanos y un banco vacío. Tiempo después, la ONG se posicionó más explícitamente sobre la cuestión de las "balas perdidas" a instancias de la muerte de una niña durante otro tiroteo en Costa Barros. Entonces, RDP condenó la indiferencia social al afirmar que "niños mueren baleados y la ciudad no llora, no protesta, no hace" (Facebook, julio 2012). La ONG también criticó la actuación policial en las comunidades expresando en sus redes sociales que, si bien la intención no era "atar de manos a la policía", no deseaban "la paz conquistada con la sangre del pobre inocente" (Facebook, agosto 2012).

\subsection{Muertes en operaciones policiales: "no fue un accidente"}

En marzo de 2014, la ayudante de servicios generales Claudia Da Silva Ferreira, de 38 años, fue baleada en las inmediaciones de su casa ubicada en el Morro de la Congonha. Media hora después, agentes de la PM subieron a Ferreira al baúl de un patrullero con el fin de hospitalizarla. Durante el trayecto, el baúl se abrió y la mujer fue arrastrada por el pavimento hasta morir. Durante la operación murió también un joven

\footnotetext{
${ }^{6}$ Una representante sindical dijo a la prensa que "los traficantes no actúan solo en los alrededores de las escuelas", en tanto "controlan el interior y los profesores o funcionarios que se resisten son amenazados y nunca más regresan" (EX, 17/07/2010).
} 
De Prácticas y discursos/ Universidad Nacional del Nordeste/ Centro de Estudios Sociales

de 16 años presentado en la prensa como un "bandido". Sobre el disparo que mató a Ferreira, circularon dos versiones contrapuestas, una sostenida por vecinos según la cual la policía "entró a los tiros", otra sostenida por la PM que esgrimía que el tiroteo se desató cuando agentes fueron "atacados por bandidos". La autopsia determinó que Ferreira murió como consecuencia del disparo sin resolver a quién pertenecía la bala.

Los vecinos de la comunidad realizaron movilizaciones que incluyeron cortes de calles, incendios de colectivos y un concurrido entierro. El hecho tuvo además inmediata repercusión en la prensa, más aún al difundirse imágenes de un aficionado que mostraban a Ferreira siendo arrastrada por el patrullero. La presidenta Rousseff se solidarizó con la familia, el gobernador calificó la acción policial como "deshumana" y el comandante de la PM se disculpó por la "conducta inadecuada" de sus subalternos (OD, 18 y 19/03/2014). En términos generales, las autoridades políticas estaduales y federales criticaron la falta de profesionalismo de los agentes involucrados y tomaron medidas como la apertura de una investigación y la exoneración del comandante al mando de la operación. Al atender que los policías involucrados poseían en su haber trece "actos de resistencia" (autos de resistência ${ }^{7}$ ), actores académicos, políticos y artísticos tematizaron al caso como una manifestación de la violencia policial ordinaria contra las personas negras y pobres. Además, fue reinstalado el debate sobre la política de "pacificación" del Estado en las comunidades pobres de la ciudad. Por último, el caso fue públicamente vinculado a otras muertes a partir de equivalencias en las formas de morir, como al caso Amarildo por la brutalidad policial o al del niño João Hélio que en 2007 fue arrastrado por la ciudad al quedar prendido a un automóvil durante un intento de robo ${ }^{8}$.

Conocida la muerte, RDP realizó una colecta para sostener a la familia de la víctima y un petitorio para que el Estado asista al grupo familiar. Asimismo, realizó una intervención con pintura roja que recorría el camino por el cual el patrullero de la PM arrastró a Ferreira. La forma de conceptualizar al caso fue similar al de las muertes producidas por "balas perdidas", sosteniendo la necesidad de preservación de la vida

\footnotetext{
7 Con "actos de resistencia" se hace referencia a una medida administrativa creada durante la dictadura militar brasileña (1964-1985) para legitimar la violencia institucional de las fuerzas policiales que posee continuidad en el posterior período democrático.

${ }^{8}$ Sobre las construcciones mediáticas ligadas al caso João Hélio, ver Silva Paiva, 2013.
} 
De Prácticas y discursos/ Universidad Nacional del Nordeste/ Centro de Estudios Sociales

durante las operaciones por tratarse de un fin superior. Incorporó también la demanda de controles a la actuación policial frente a la cantidad de actos de resistencia de los policías involucrados.

\subsection{Muertes de policías: "muerto por trabajar en condición deshumana"}

En marzo de 2014, un subcomandante de la UPP, Leidson Acacio Alves Silva, fue asesinado de un disparo en la frente en el Complexo da Penha. Fue el tercer agente muerto aquella semana en la región en un contexto de "ataques" a policías en zonas "pacificadas". El secretario de Seguridad estadual dispuso de un refuerzo de policías y de agentes de la BOPE para la zona. También aseguró que "la ciudad vive una guerra", que el "programa de la UPP no está amenazado" y deslizó que la orden de atacar policías provino de los penales (OD y EX, 14/03/2014). Ante este despliegue de seguridad, manifestando temor a nuevos actos de violencia, vecinos y organizaciones sociales realizaron una asamblea en Nueva Brasilia.

La organización RDP incorporó la denuncia de homicidios de policías "en servicio", rechazando en el sostenimiento de esta causa las imputaciones de parcialidad realizadas al movimiento de derechos humanos y disputando sentidos en el campo de organizaciones civiles. En este sentido, Costa enumeró en su blog acciones realizadas por RDP con miras a "no excluir la vida de esos profesionales del concepto de dignidad de la vida humana" (Blog Palabra Plena, abril 2014). La muerte de policías "en servicio", entre las cuales incluyen la de Alves Silva, es para RDP una manifestación de una política de seguridad incompleta: los policías morían porque para las autoridades "la violencia que devora vidas humanas debe ser resuelta solo por la policía" (Blog RDP, agosto 2013). Finalmente, RDP demanda que el Estado valore y resguarde la vida de los policías, al impedir que trabajen en "condiciones deshumanas" y que "paguen con su sangre el sueño de la pacificación" (Facebook, marzo 2014).

\subsection{Muertes de garantes de la democracia: "el tiro golpeó en nuestros ojos"}

En febrero de 2014, en la continuidad del ciclo de protestas iniciado en 2013, se desarrolló en el centro de la ciudad una manifestación contra el aumento del 
De Prácticas y discursos/ Universidad Nacional del Nordeste/ Centro de Estudios Sociales

transporte público que desembocó en un enfrentamiento entre manifestantes y la policía. En este contexto, el camarógrafo de televisión Santiago Andrade fue alcanzado por un artefacto pirotécnico, hecho que provocó su muerte días después.

Con la muerte de Andrade, la seguridad de los periodistas devino tema de discusión pública. Durante el velatorio, colegas del camarógrafo utilizaron remeras con la leyenda "podría haber sido cualquiera de nosotros", mientras la prensa difundía informes sobre los riesgos de ejercer la profesión en el país. La muerte de Andrade suscitó el posicionamiento de organizaciones de prensa locales e internacionales destacando la responsabilidad del Estado de brindar garantías a los periodistas y de las empresas de proteger a sus trabajadores ${ }^{9}$. Tiempo después, la Asociación Brasileña de Emisoras de Radio y Televisión reconoció que luego de la muerte del camarógrafo el gobierno "reforzó las medidas de protección a periodistas en las manifestaciones" (JB, 08/10/2014). A través de estas intervenciones la muerte de Andrade fue transformada en símbolo del compromiso periodístico y en manifestación de la necesidad de proteger a los periodistas para que cumplan su función social. Pero también se transformó en una bandera de lucha contra la violencia en las manifestaciones, que en los hechos se tradujo en una reacción contra grupos considerados radicalizados ${ }^{10}$. El gobernador del estado repudió "la violencia" porque "la libertad de prensa es un bien que debe prevalecer como instrumento del ejercicio de la democracia" (OD, 10/02/2014). Por su parte, la presidenta Rousseff apoyó "la libertad de manifestar", pero criticó "la violencia" y "el anonimato", al tiempo que adelantó que su gobierno trabajaría en un protocolo de actuación policial en protestas (OD, 17/02/2014). En correspondencia con estas declaraciones, la Justicia detuvo a manifestantes acusados de "homicidio triplemente calificado" y de "promover la violencia en las protestas". Asimismo, funcionarios políticos estaduales y nacionales presentaron proyectos para "regular la protesta social", algunos tipificados como "leyes antiterroristas". En este

\footnotetext{
${ }^{9}$ Este debate rehabilitó parcialmente el desatado con la muerte del periodista de la Red O Globo, Tim Lopes, en el Complexo do Alemão en 2002. Ver Silva Paiva, 2013.

10 Particularmente al Black Bloc, grupo de jóvenes que usaban máscaras, se vestían de negro y atacaban "símbolos del capitalismo". Este grupo era destacado como el brazo más combativo de las protestas iniciadas en 2013.
} 
De Prácticas y discursos/ Universidad Nacional del Nordeste/ Centro de Estudios Sociales

contexto, políticos, periodistas, académicos y activistas debatieron en torno a los límites de la protesta y a los valores de la democracia.

RDP realizó un homenaje a Andrade en la playa de Copacabana, en el cual una cámara solitaria apuntaba hacia el piso acompañada de una pancarta que expresaba "en memoria de quien murió en el ejercicio de una profesión indispensable para la democracia". En declaraciones a la prensa, Antônio Costa solicitó a los poderes públicos "ofrecer condiciones de trabajo seguras" al periodismo por considerarlo "una de las principales salvaguardas de la democracia" (OD, 13/02/2014). Cabe destacar que este lenguaje también fue utilizado como reacción al asesinato de una jueza a manos de policías investigados por corrupción y ante la muerte de un camarógrafo de televisión durante una operación policial, ambos hechos ocurridos en 2011.

\section{Reflexiones finales}

La muerte producida por homicidios ocupa un lugar central para Rio de Paz en términos prácticos y simbólicos. Esta centralidad se evidencia en el discurso institucional que vincula la creación de la organización a una reacción frente a una "ola de muertes ocurrida en Rio de Janeiro". Asimismo, se manifiesta en la recurrente apelación a las cifras de los homicidios ocurridos en el Estado que la misma organización recopila. Además, la muerte es el concepto medular en el lenguaje público utilizado por RDP en tanto son recurrentes las apelaciones explícitas a cuerpos sin vida, a rituales mortuorios y a otros recursos dramáticos. En esta dirección, la denuncia de la ocurrencia de homicidios, así como la crítica a la indiferencia social y política frente a la magnitud atribuida a este problema, constituye el centro de las valoraciones morales de RDP. Más aún, la necesidad de reasignar valor a la vida aparece como la motivación fundamental del activismo de esta organización.

En este orden de cosas, cabe destacar la realización por parte de la ONG de operaciones de generalización de las muertes producidas por homicidios. Se trata de operaciones basadas en la agregación de muertes bajo la premisa "todos los homicidios son condenables". Además, se evidencian operaciones que abstraen a la muerte de los fallecidos -y sus características- bajo la intención de "hacer oposición a la 
De Prácticas y discursos/ Universidad Nacional del Nordeste/ Centro de Estudios Sociales

muerte" -en general- y de "luchar por la vida" -en general-. En este sentido, la más evidente operación de generalización es la vinculación de las muertes al problema público de la violencia urbana y a la política de "pacificación" sostenida por la instancia estadual como respuesta política al problema. Estas operaciones de generalización influyen en la forma en la cual RDP entiende a la violencia como problema público porque la denuncia de los homicidios en términos genéricos dificulta la emergencia de procesos de atribución de responsabilidades causales puntuales, al tiempo que habilita lecturas estructurales del problema.

Simultáneamente, Rio de Paz realiza operaciones de clasificación de las muertes sobre la base de diversos criterios. En la producción de estadísticas sobre "violaciones a los derechos humanos", por ejemplo, la ONG manifiesta un ejercicio de conteo y categorización de muertes: "homicidios dolosos", "lesiones corporales seguidas de muerte", "latrocinios", "homicidios producto de intervenciones policiales", "policías militares muertos en servicio" y "policías civiles muertos en servicio". Además, desde RDP clasifican muertes al describir homicidios según formas de morir, por "balas perdidas", en "operaciones militares", "en servicio", con "desaparición del cuerpo". Apelar a características de quienes mueren también implica operaciones de clasificación: "policías", "niños", "pobres", "garantes de la democracia". Finalmente, otra clasificación se vincula a la selección entre los homicidios producidos de aquellos por los cuales la ONG se expresará en el espacio público. En este último sentido, desde la ONG son priorizados los homicidios que estiman posibilitarían una reflexión general sobre la violencia o alguna de sus dimensiones.

Sostenemos que el análisis de la práctica concreta de esta ONG ubicada en el contexto de la experiencia pública más general permite particularizar dimensiones implicadas en la violencia urbana entendida como problema público en la región metropolitana de Rio de Janeiro: actores, repertorios de acción colectiva, valoraciones, categorizaciones. En este sentido, observamos en la práctica de RDP con relación a la ocurrencia de homicidios dimensiones que complejizan a la violencia urbana como problema público sin atentar a su concepción como una (sola) unidad de sentido. Más aún, el análisis permite observar que bajo el paraguas de la violencia urbana como 
De Prácticas y discursos/ Universidad Nacional del Nordeste/ Centro de Estudios Sociales

problema marco son conformados diversos sub-problemas públicos a través de dinámicas de la que participan una multiplicidad de actores. Es decir, dimensiones con algunos grados de autonomía que se vuelven objeto de políticas públicas, con actores específicos y dinámicas propias, como por ejemplo la política de pacificación de comunidades, el riesgo en las escuelas públicas o la seguridad de los trabajadores de la prensa en las manifestaciones.

\section{Bibliografía}

Alves, D.; Alexandre, M.; Gonçalves Lacerda, E. y de Ávila Chaves Borges, F. (2013). Os jovens e as mortes por homicídio na Região Metropolitana do Rio de Janeiro 19982007. Em Teixeira de Andrade, L.; Borges de Souza, D. y Miranda de A. Freire, F. H. (orgs.) Homicídios nas regiões metropolitanas. Rio de Janeiro: Letra Capital.

Arosi, A. P. (2013). Os usos da categoria vítima: o caso dos movimentos de familiares de vítimas de violência no Rio Grande do Sul e no Rio de Janeiro. Interseções, Vol. 15, $\mathrm{N}^{\circ} 2$, pp. 356-373.

Cano, I. y Ribeiro, E. (2007). Homicídios no Rio de Janeiro e no Brasil: dados, políticas públicas e perspectivas. En Gonçalves Da Cruz, M. V. y Cerqueira Batitucci, E. (orgs.) Homicídios no Brasil. Rio de Janeiro: FGV, pp. 51-78.

François, B. y Neveu, É. (1999). Espaces publics mosaïques. Acteurs, arènes et rhétoriques des débats publics contemporains. Rennes: Presses Universitaires de Rennes.

Galar, S. (2015). Espacios públicos locales e inseguridad: reconfiguraciones a partir de casos conmocionantes en capitales provinciales (La Plata y Mendoza, 2005-2013). Tesis de doctorado en ciencias sociales, Universidad Nacional de La Plata.

Gusfield, J. (2014). La cultura de los problemas públicos. Buenos Aires: Siglo XXI.

Kant de Lima, R.; Misse, M. y Mendes de Miranda, A. P. (2000). Violência, Criminalidade, Segurança Pública e Justiça Criminal no Brasil: Uma Bibliografia. Revista Brasileira de Informação Bibliográfica em Ciências Sociais, N 50, pp. 45-123. 
De Prácticas y discursos/ Universidad Nacional del Nordeste/ Centro de Estudios Sociales

Landim, L. y Siqueira, R. (2013). Trajetos da Violência, da Segurança Pública e da Sociedade Civil na Cidade do Rio de Janeiro. Brasília: Instituto de Pesquisa Econômica Aplicada.

Mendez De Miranda, A. y Pita, M. V. (2011). Rotinas burocráticas e linguagens do estado: políticas de registros estatísticos criminais sobre mortes violentas no Rio de Janeiro e em Buenos Aires. Sociología Política, Vol. 19, N 40, pp. 59-81.

Misse, M. (2011). Crime organizado e crime comum no Rio de Janeiro: diferenças e afinidades. Revista de Sociologia e Política, Vol. 19, № 40, pp. 13-25.

Pereyra, S. (2013). Política y transparencia. La corrupción como problema público. Buenos Aires: Siglo XXI Editores.

Rojido Fiori, E. (2014). Políticas de seguridad en el Brasil de los mega-eventos. Cuestiones de Sociología, Nº10, pp. 53-66.

Schillagi, C. (2011). Problemas públicos, casos resonantes y escándalos. Algunos elementos para una discusión teórica. Polis Revista de la Universidad Bolivariana, Vol. $10, N^{\circ} 30$, pp. $245-266$.

Serrano Berthet, R. y Chioda, L. (2012). Por um Brasil mais seguro: uma análise da dinâmica do crime e da violência. Revista Brasileira de Segurança pública, Vol. 6, N 1, pp. 172-202.

Silva Paiva, L. F. (2013). Os significados da morte: os discursos dos meios de comunicação sobre crimes que abalaram o Brasil. Tesis de doctorado presentada em Universidad Federal de Ceará, Departamento de Ciencias Sociales, Programa de Postgrado en Sociología.

Vainer, C. (2010). Cidade de Exceção. Reflexões a partir do Rio de Janeiro. Rio de Janeiro: Mimeo.

Waiselfisz, J. J. (2013). Homicídios e Juventude no Brasil. Mapa da Violência 2013. Brasília: Secretaria-Geral da Presidência da República. 